\title{
REMOTE SENSING TECHNIQUES IN THE SEARCH FOR ANCIENT SHIPWRECKS: HOW TO DISTINGUISH A WRECK FROM A ROCK IN GEOPHYSICAL RECORDINGS
}

\author{
Sakellariou D. ${ }^{1}$ \\ Institute of Oceanography, Hellenic Centre for Marine Research, Anavyssos, Greece, \\ sakell@ath.hcmr.gr
}

\begin{abstract}
This paper presents the way conventional marine geophysical methods may be used with the highest efficiency for deep-water archaeological research, especially for the detection of ancient shipwrecks. Their use becomes all the more effective, when the principles of oceanography and marine geology are being followed during the interpretation of the geophysical recordings. The integration of sub-bottom profiling data provides valuable information on the geological structure of the seafloor's shallow substrate, which are an almost absolute prerequisite for a geologically reasonable interpretation of the side scan sonar images. Otherwise, interpretation of the sonar recordings may be erroneous or may be in direct discrepancy with the shallow sub-seafloor geological structure. Limitations of the efficiency of the geophysical methods in the case of targets of biogenic or anthropogenic origin or in shallow water environments are also being discussed.
\end{abstract}

Key words: Underwater archaeology, Side scan sonar, subbottom profiler, geologic interpretation.

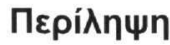

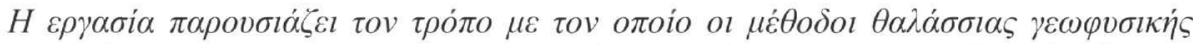

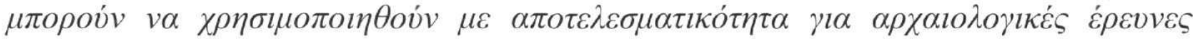

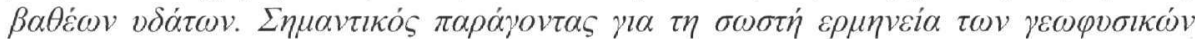

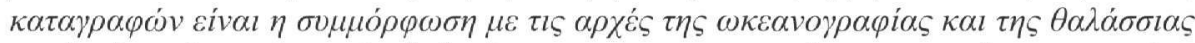

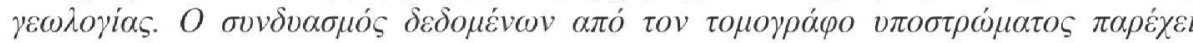

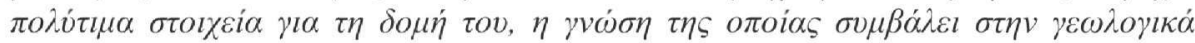

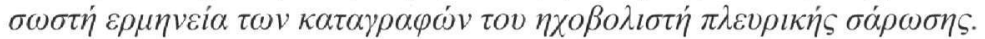

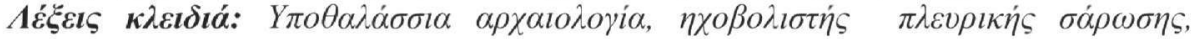

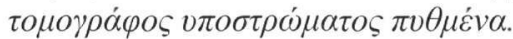

\section{Introduction}

The aim of this paper is to evaluate the way, marine geophysical methods and geologicaloceanographic interpretation of the geophysical recordings should be used and followed, in order to become a powerful tool in deep-water archaeological research. Limitations of the efficiency of the same methods in shallow water are also discussed. The conclusion presented herewith are drawn from thE experience we gained during the over twenty research cruises (over 200 days 
shiptime) devoted to the search for ancient shipwrecks in the last six years in the frame of the collaboration of the Ephorate of Underwater Antiquities (EUA) of the Greek Ministry of Culture and the Hellenic Centre for Marine Research (HCMR).

It is widely accepted that remote-sensing techniques are a powerful tool in deep-water archaeological research (Ballard et al. 2000, Quinn et al. 2002a, Quinn et al. 2002b, Chalari et al. 2003, Blondel and Pouliquen 2004, Papatheodorou et al. 2001, 2005, Sakellariou et al. 2006, 2007), especially at depths beyond the range of scuba-diving. Quinn et al. (2000) describe adequately the principles of the operation of side scan sonar, sub-bottom profiler and magnetometer and the advantages of using geophysical equipment to record submerged and buried archaeological resources. Nevertheless, the majority of the published works refer to the detection of relatively recent, wooden- or iron-made wrecked ships, the hull of which is rather complete or relatively well preserved and commonly rises well above the seafloor (Hobbs at al. 1994, Barto Arnold III et al. 1999), or to the geophysical investigation of already known submerged archaeological sites (Quinn et al. 1997, 1998).

In the case of ancient shipwrecks, which were the target of the joined EUA-HCMR research cruises, remnants on the seafloor are most commonly restricted to the cargo of the wrecked vessels and not the vessel itself. In cases of merchant ships, which are the majority of ancient wrecks found up to date, the cargo was composed mainly of amphorae and pottery. In areas of low sedimentation rate the amphorae lie scattered on the seabed or form a longitudinal topographic high, gently rising above the seafloor. Structures like that are being recorded on the side scan sonographs as strongly reflecting/backscattering features, very similar to low relief rocky outcrops.

\section{Materials and Methods}

In the first 3 to 4 years of the joined EUA-HCMR research cruises, the investigation of the sea-bed was mainly based on side scan sonar prospecting solely. Remotely operated vehicles (ROVs) and the two-person submersible Thetis, operating from the research vessel Aegaeo, were used for the visual inspection of the selected sonar targets. Although priority was given to depths exceeding the depth range of scuba diving, the majority of the 20 wrecks discovered till then, has been found rather accidentally or was discovered following information provided by fishermen and old sponge-divers, at depths shallower than $50 \mathrm{~m}$, close to rocky coasts. Only two out of hundreds of visually inspected sonar targets were proved to correspond to ancient wrecks.

In 2004, sub-bottom profiling was emerged to a basic tool of the join research effort of EUA and HCMR. Integration of the sub-bottom profiling data resulted to a major qualitative and quantitative improvement of the effectiveness of the undertaken research efforts. Consequently, the previously almost purposeless consumed ship-time in unsuccessful ROV and submersible dives was drastically eliminated for the benefit of the systematic survey of larger areas.

Marine geophysical instrumentation of both surveys incorporated a side scan sonar system and a $3.5 \mathrm{kHz}$ sub-bottom profiler. The side scan sonar system was composed of a Geoacoustics Ltd two-channel, dual frequency tow-fish, an electro-hydraulic winch with $1800 \mathrm{~m}$ tow-cable and a Geoacoustics side-scan-transceiver. The sonar's tow-fish was being deployed from the A-frame placed at the stern of the vessel. Sonar data were being recorded on paper film by an EPC Model 1048 2-channel analog recorder - serving also as trigger for the side scan sonar - and digitally by using Isis Sonar v.6.41 software by Triton Imaging, Inc.

The operating frequency during the side scan sonar survey was $100 \mathrm{kHz}$ and the swath width about $190 \mathrm{~m}$ (95 m per channel) at a shooting rate of $0.125 \mathrm{sec}-8$ pings per second. By the $150 \mathrm{~m}$ spacing of the survey lines we managed to maintain about $25 \%$ overlapping of the sonar coverage between the adjacent lines. The vessel's speed was more or less constant at $2.5 \mathrm{knots}(1.25 \mathrm{~m} / \mathrm{sec})$ and the height of the tow-fish from the sea-floor between 10-15 m. Assuming a sound speed of $1500 \mathrm{~m} / \mathrm{sec}$ in the water, at the shooting rate of $0.125 \mathrm{sec}$, swath width of $190 \mathrm{~m}$ and vessel's speed 
of $1.25 \mathrm{~m} / \mathrm{sec}$, the sonar system may provide maximum along-track resolution of $15-20 \mathrm{~cm}$ and maximum across-track resolution of $20-40 \mathrm{~cm}$.

The $3.5 \mathrm{kHz}$ sub-bottom profiler used for the survey was composed by an ORE 4-array transducer tow-fish associated with a Geoacoustics Ltd., Model 5210A geopulse receiver and a Model 5430A geopulse transmitter. The profiler's tow-fish was being hanging from the stern-crane off the port side of the vessel at $2 \mathrm{~m}$ below the sea-surface. Sub-bottom profiling data were digitally acquired using Delph Seismict software, geo-encoded using Delph Map v. 2.9.6 software and postprocessed using SeismicGIS software of Triton Imaging Inc. Sub-bottom profiling and side scan sonar survey were conducted synchronously, along the same track-lines. The profiler was operating at a frequency of $3.5 \mathrm{kHz}$ and at various shooting rates (125 mesc to $1 \mathrm{sec}$ ) depending the depth of the survey area, and pulse duration of $2 \mathrm{~ms}$.

The purpose of using the sub-bottom profiler for this kind of surveys is rather the need for collecting as much information about the natural-geological characteristics of the sea-floor and its substrate as possible and not to "detect" the possible wrecks on the recordings of the profiler. The in-depth knowledge of the marine geological factors, which form the structure of the sea-floor and its substrate is of paramount importance and helps greatly, when interpreting the side scan sonar recordings, especially the nature of the sea-bed and the selected targets.

Two remotely operated vehicles, the working class MaxRover (max depth $2000 \mathrm{~m}$ ) and the observation class Super Achilles (max depth $1000 \mathrm{~m}$ ), and the two-manned submersible THETIS (max depth $610 \mathrm{~m}$ ) of HCMR were used for diving and visually inspecting the selected targets of interest on the sea-bed and eventually for collecting artifacts.

\section{Interpretation of Geophysical Data}

\subsection{Wrecks and Rocks}

Figure 1A is a schematic visualization of a side scan sonar survey with two prominent targets, rising gently above the flat seafloor. Both targets A and B display significantly higher backscatter in respect to the surrounding seafloor, they have similar shape and thus may well be selected as promising ones. From the side scan sonar data one can hardly draw any conclusions on the origin of the targets, since no information on the geologic structure of the seafloor's substrate are available. Figure 1B visualizes a possible geologic, sub-seafloor structure of the previous area as recorded by a sub-bottom profiler, like a $3.5 \mathrm{kHz}$ one. From the profiler's data and the acquired geologic section of the sub-seafloor one can easily recognize that target A coincides with the occurrence of the hard substrate (acoustic basement for $3.5 \mathrm{kHz}$ profiler) on the seafloor.

Opposite to target A, target B in Fig. 1B represents a feature located on the seafloor at a site underlain by Holocene sediments. Integration of side scan sonar and subbottom profiling data, like the ones described here enables more realistic and geologically correct interpretation of the sonar targets. It also saves ROV and/or submersible dives to false interpreted targets. Thus, if subbottom profiling data were not available, a possible ROV dive to visually inspect target A would end up with a picture like the one shown in Fig. 1C. Several hours of costly shiptime would have been spent just to discover rocks and rock pieces on the seafloor. Fig. 1D shows the happy end of the visually inspection of a target, like target $\mathrm{B}$ of Fig. $1 \mathrm{~A}$ and $\mathrm{B}$, selected on the base of the integration of side scan sonar and subbottom profiling data and a geologically correct interpretation of its origin. Several hundreds of ancient amphorae, like the ones shown in Fig. 1D, form a morphologically low, acoustically high backscattering feature on the flat, low backscattering seafloor.

The overall configuration shown in Fig. 1 may be schematic and theoretical, but is also very realistic. Fig. 2a shows a side scan sonar record from the straits between Chios and Oinouses islands. From the sonar records alone one would easily recognize the presence of the rocky basement on the seafloor. The basement is seen as a strongly backscattering area displayed in dark 

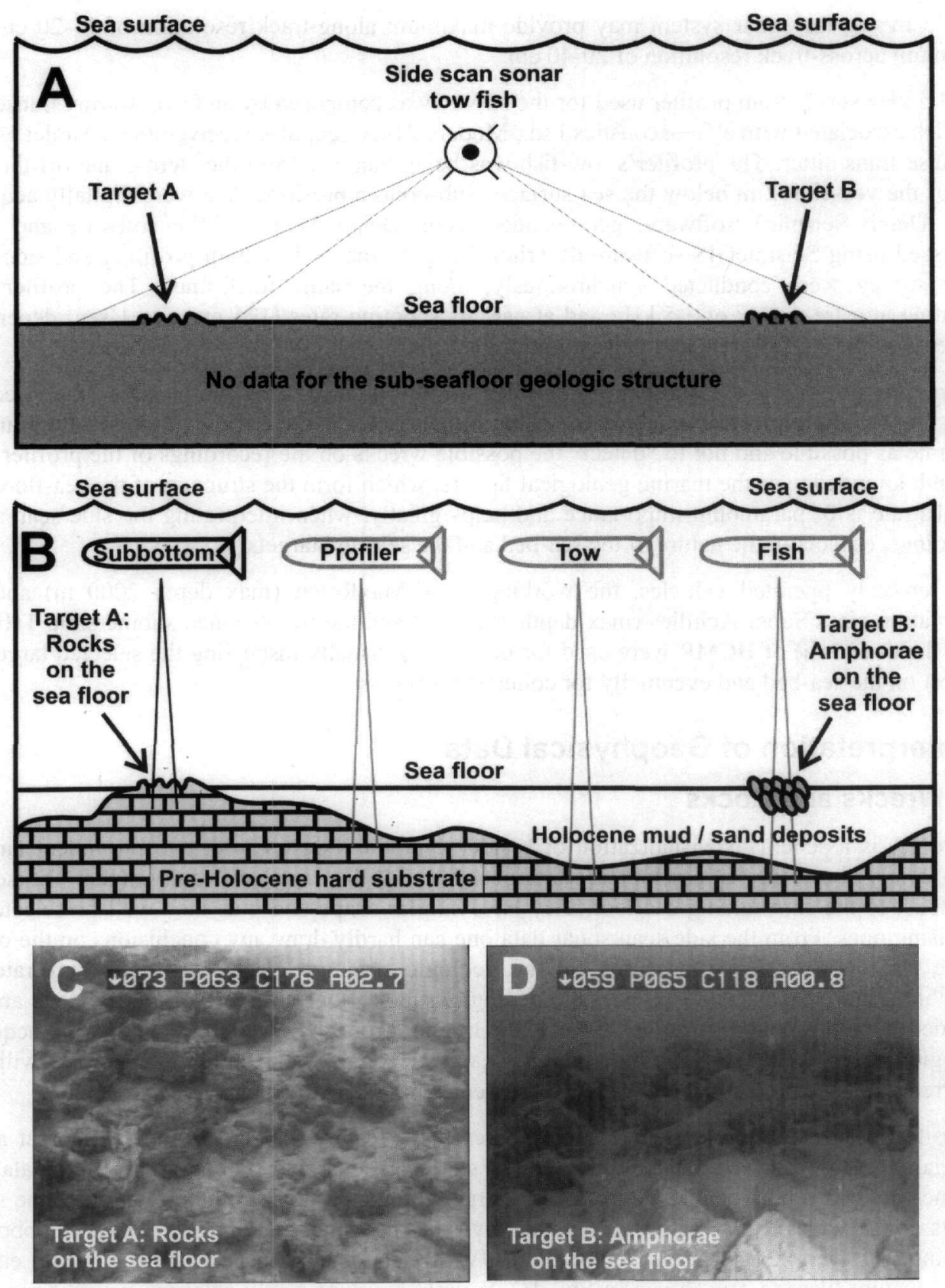

Figure 1 - a: Schematic presentation of a side scan sonar survey. Targets $A$ and $B$ represent low morphological, high backscattering irregularities on the seafloor. b: Schematic presentation of a subbottom profiling survey in the same area. $c$ and $d$ show how targets $A$ and $B$ respectively could look like. Both pictures were taken at about $70 \mathrm{~m}$ depth

gray tones. Variations of the color tones originate from the roughness and the irregular relief of the basement outcrop, while lighter gray tones may come from small silt or sand pockets on the basement. Nevertheless one would also easily, and reasonably, misinterpret the target, pointed by arrows in the center of the record, as rocky outcrop too, since the hard basement appears to be at very shallow depth below the seafloor of the area and may often rise through the thin(?) sedimentary cover. On the sonograph, the target itself was interpreted as a $17 \mathrm{~m}$ long by $7-8 \mathrm{~m}$ 
wide and 1.5-2 m high, gentle culmination, sitting on a low backscatter (light gray tone) flat seafloor.

The combination of sub-seafloor data, obtained by subbottom profiling (Fig. 2B) performed simultaneously with the sonar survey, falsifies the above interpretation. The target was imaged by the sub-bottom profiler, since it was accidentally located on the vessels track. But what is more important is that it became evident from the data of the subbottom profiler that the site of the target is underlain by several meters thick sedimentary deposits, which cover the Pre-Holocene hard ground. Hence, the possibility of another basement outcrop on the seafloor was immediately excluded.
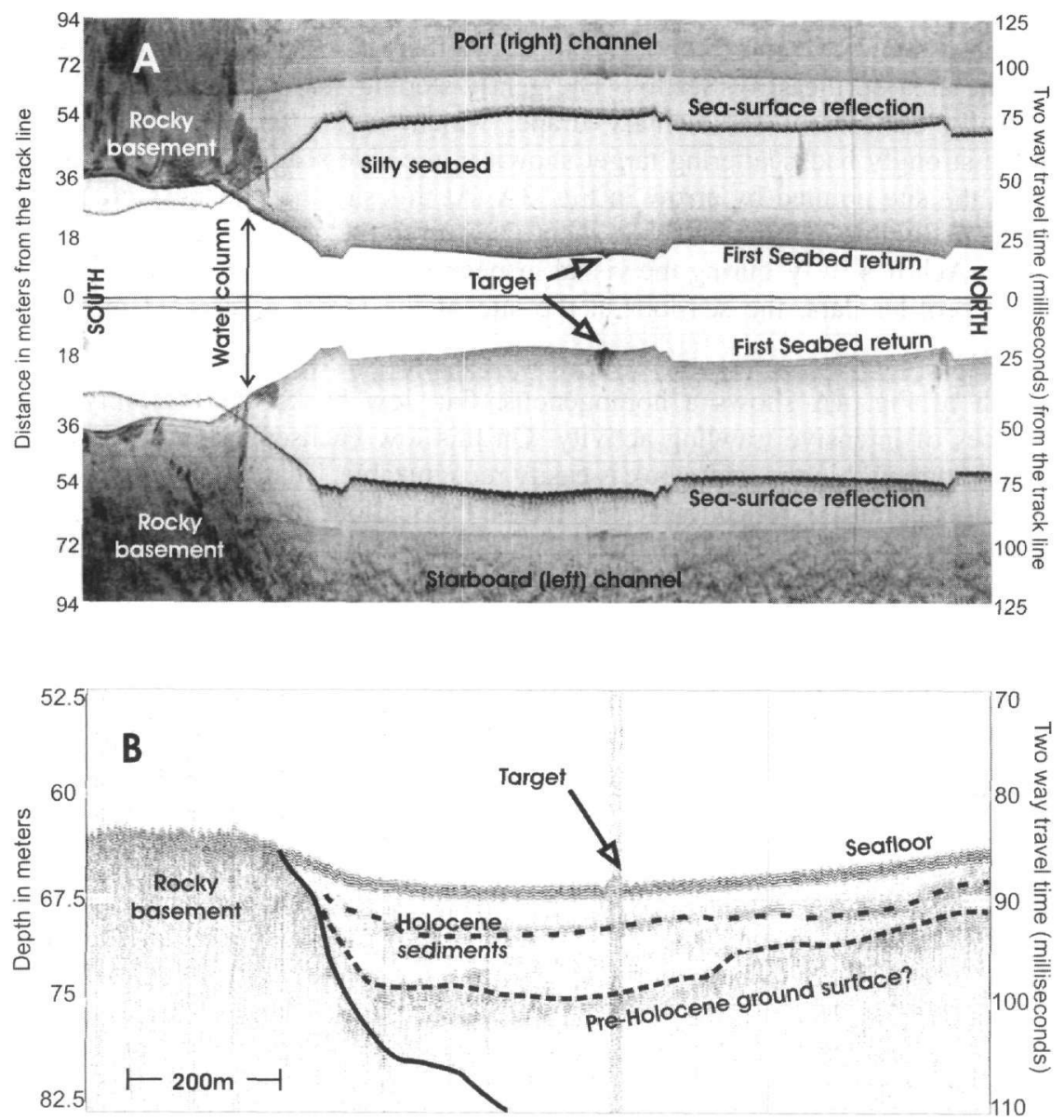

Figure 2 - A: Side scan sonar image (100 kHz, 125 msecs) showing a flat, homogenous, low backscattering (light grey) seafloor, covered by silt deposits. The strongly backscattering (dark grey) area at the left side of the record derives from hard rocks outcroping on the seafloor. The target in the centre of the record (arrows) is a low morphological high with strong backscatter. B: Interpretation of a $3.5 \mathrm{kHz}$ sub-bottom profile acquired at 125 milliseconds key-rate along the central line of the sonar record shown in Fig. $2 \mathrm{~A}$. The acoustic basement acquired at the left part of the profile coincides with the rocky outcrop shown on the sonar record of Fig $1 \mathrm{~A}$. The 5-7 $\mathrm{m}$ thick Holocene, acoustically transparent deposits shown on the profile coincide with the weakly reflecting, flat seafloor of Fig. $2 \mathrm{~A}$. The target indicated by arrows on the sonograph and the profile lies on top of the Holocene deposits (from Sakellariou et al. 2007) 
The visual inspection of this target is shown in Fig. 1D and was proved to be an ancient shipwreck. Over 400 hundred amphorae, belonging to two main types, i.e. Chian and an as yet unidentified type, originating probably from an adjacent production center, and pottery, made up the cargo of the ancient ship, which wrecked round the middle of the $4^{\text {th }}$ century BC in the Chios-Oinousses strait (Kourkoumelis et al. 2005). This wreck possibly would have not been discovered, if the respective sonar target would have been interpreted as rocky outcrop. Thus, interpretation of the sonographs alone, without the assistance of data on the nature of the seafloor's substrate, may lead more often than not to the misinterpretation of sonar targets. As a result, numerous ROV and submersible dives may end up with the 'discovery' of rocky outcrops on the seabed, while shipwrecks may not be discovered because some other targets might be falsely ignored.

The Figs 3 and 4 show two more, opposite to each other, cases. Figure $3 \mathrm{a}$ displays a $3.5 \mathrm{kHz}$ profile from the area northeast of Serifos. The gently sloping seafloor is covered by a relatively thin, acoustically transparent sedimentary drape, which covers the acoustically opaque hard basement. The strongly backscattering target shown in the side scan sonar image of Fig. 3B was acquired from the site pointed by arrow in Fig. 3A. At this site the thickness of the sedimentary cover becomes negligible and the hard basement rises up to the seafloor. Fig. $3 \mathrm{C}$ shows a picture taken by Super Achilles ROV during the visual inspection of the target. As already assumed from the subbottom profiler data, the seafloor at the site of the target is covered by rock pieces of various sizes.

The sonograph of Fig. 4A shows a homogenous, flat, low backscattering, silty seafloor with prominent traces of intensive trawling activity. On this low backscattering seafloor the strongly reverberating feature within the white box is easily recognizable. That feature consists of a number of high amplitude, point-like reflections, scattered on the seafloor in an area of $20 \mathrm{~m}$ by $20 \mathrm{~m}$. The main body of the target displays higher backscatter (darker color) than the surrounding seafloor, indicating a slight change of the nature of the seabed. A NNW-SSE trending trawling scar forms the western limit of the target. Figure 4B shows a characteristic $3.5 \mathrm{kHz}$ sub-bottom profile acquired from the survey area. The substrate of the seafloor is composed of transparent acoustic packages separated by medium and low amplitude reflectors, running parallel to the seafloor. The transparent packages may represent silt or clay deposits, while the medium and low amplitude reflectors may derive from coarser grain deposits. The seismic stratigraphy of the seafloor's substrate implies continuous sedimentation for at least the upper 25-30 milliseconds (15-20 m) below the seafloor. No hard basement was observed on any of the acquired seismic profiles in the survey area.

In the light of the subbottom profiling data for the shallow sub-seafloor structure (Fig. 4B) the recorded target is not likely to have derived from any rocky outcrop on the seafloor. Thus, the strong, point-like reflections and the moderately reflecting main body of the target should have derived from any kind of small objects, lying on the seafloor or at very shallow depth below it. The target was visually inspected by THETIS submersible. Several tens of ancient amphorae were lying on the seafloor, semi-buried within the mud sediments. Some of the amphorae have been shifted by several meters, leaving on the soft seafloor a shaLlow furrow behind them, as a trace of their transport. Shifting of the amphorae may be attributed to the trawling activity in the area and it may occur, when the half-buried amphorae are being caught by the cod net of the trawl. The visually observed distribution of the amphorae on the seafloor allows a reinterpretation of the shape and the acoustic character of the inspected target. Each single, point-like, strong reflection of the target is very likely to have derived from every single amphora, which rises above the seafloor.

\subsection{Targets of Biogenic Origin}

Following the examples described in the previous chapter one may think that every high backscatter feature, acquired as prominent target in the side scan sonar recordings and located on sedimentary deposits, may with very high consistency have derived from ancient shipwreck. Unfortunately this is not the case. 

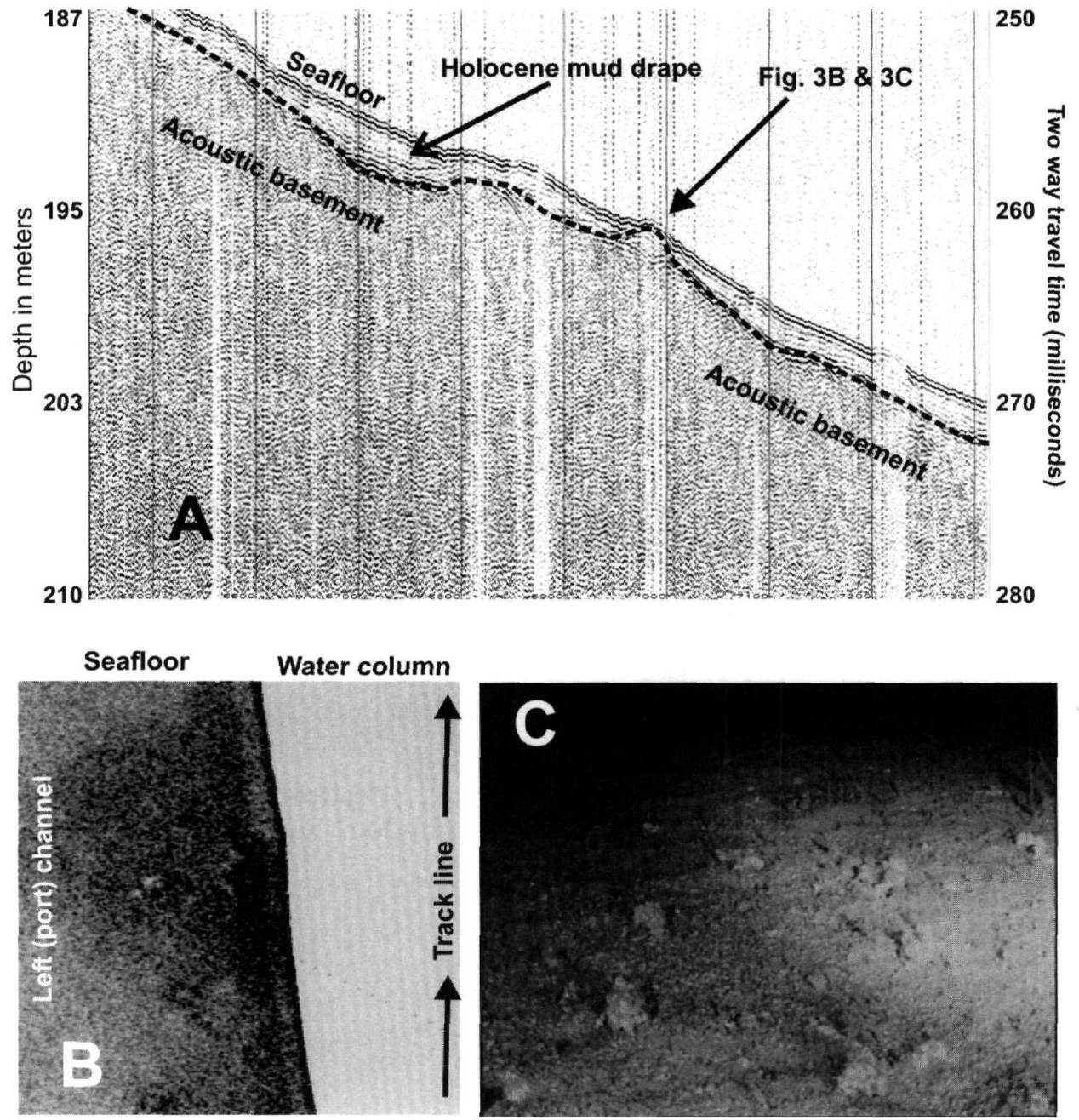

Figure 3 - A: Section of a $3.5 \mathrm{kHz}$ subbottom profile from northeast Serifos area. A 1-2m thick acoustically transparent sedimentary drape covers the hard substrate, acquired as acoustic basement. B: Side scan sonar image from the site pointed by the arrow in Fig. $3 \mathrm{~A}$. High backscatter feature acquired from the port (left) channel close to the track line. C: Photograph of the seafloor at the site of the target, taken during the visual inspection by ROV Super Achilles. Rocks and rock pieces lying on the seafloor, are coincident with the interpretation of the $3.5 \mathrm{kHz}$ profile of Fig. $3 \mathrm{~A}$

A $3.5 \mathrm{kHz}$ subbottom profile is presented in Fig. 5A, acquired in June 2005 in the straits between North Evia and Magnesia Peninsula. According to the sub-seafloor data the area is characterized by the presence of a several meters thick sedimentary drape of presumably Holocene age, which covers unconformably older, inclined strata. The unconformity is marked as high amplitude reflector, which forms the bottom of the transparent drape. A dozen of interesting or promising targets were identified on the side scan sonar recordings, acquired during the cruise from this area. The possibility the selected targets to represent outcrops of rocky formations was correctly excluded from the beginning on, since the Holocene drape covers the entire surveyed area. At the end of the survey, after many ROV dives and visual inspection of over twelve targets none of them was proved to be of any archaeological significance. The majority of the visually inspected targets was of biogenic origin while the rest of recent anthropogenic origin. 
Two way travel-time from the tow-fish (msec)
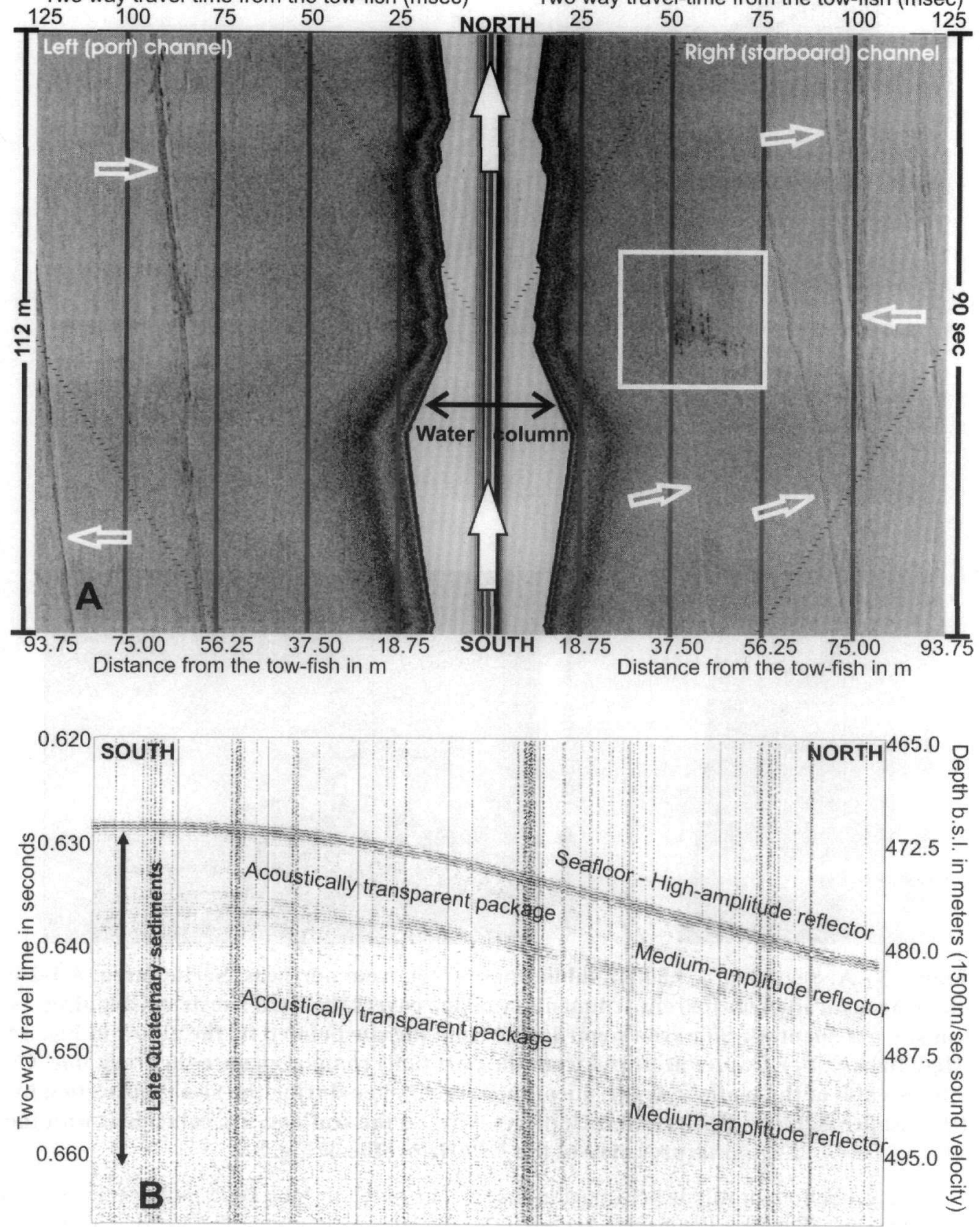

Figure 4 - A: Side scan sonar record from the area west of Kythnos island. ThE image shows a weakly backscattering seafloor with prominent traces (arrows) of intensive trawling activity. The white square delineates a feature composed of strongly backscattering single points. B: Section of $3.5 \mathrm{kHz}$ profile acquired simultaneously and along the track line of the sonar image. The seafloor of the surveyed area is underlain by acoustically transparent sedimentary deposits. No hard basement is being observed, excluding thus the possibility the target shown in Fig. 4A to represent rocky outcrop (from Sakellariou et al. 2007) 

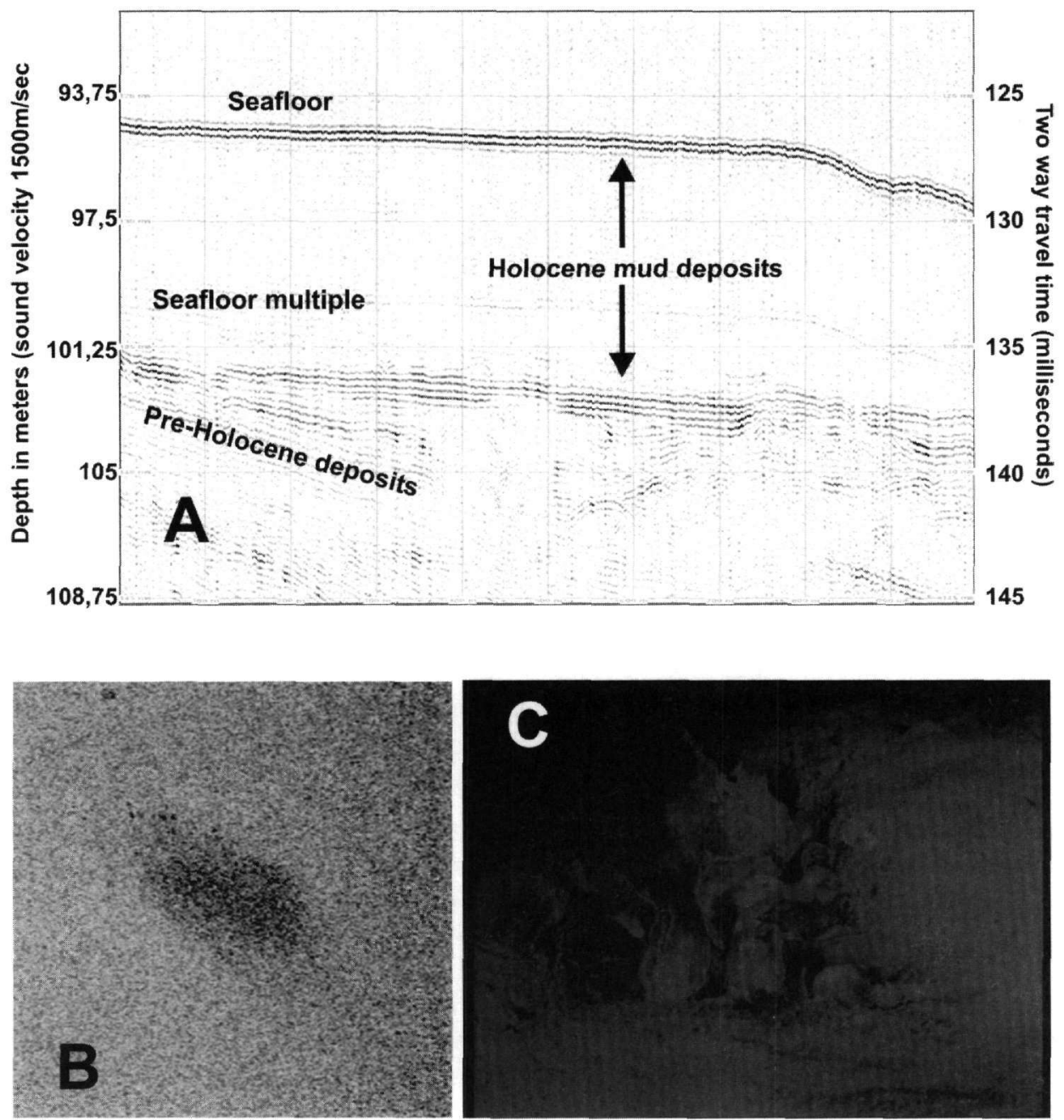

Figure 5 - A: Section of $3.5 \mathrm{kHz}$ subbottom profile from the Oreoi straits, North Evia. The profile shows the 6-meters thick, acoustically transparent, Holocene sedimentary drape overlying unconformably Pre-Holocene deposits. B: Extract from a side scan sonar record showing a strongly backscattering target from the area where the profile of Fig. $5 \mathrm{~A}$ was acquired. C: Photograph taken by ROV Super Achilles during the visual inspection of the previous target. The target was proved to be a concentration of living bivalves and various shells on the seafloor

Figure 5B shows one of the targets selected to be visually inspected. The acoustic character of the target is fairly similar to the one of the target of Fig. 4A. It is composed of many, strongly backscattering single points, and its overall shape is elongate with $15 \mathrm{~m}$ length and $8 \mathrm{~m}$ width. These dimensions would fit fairly well with the ones of the ancient ships, so the expectations were very high. Figure $5 \mathrm{C}$ shows the result of the visual inspection of the target. Its high backscatter has derived from the presence of numerous living organisms and shells of various sizes lying on the silty seafloor. Other, similarly promising targets were proven to be concentration of small hills or shallow holes of a few tens of centimeters in diameter, possibly originated from the activities of living organisms on the seafloor. Features of anthropogenic origin like rubbish, fishing nets, tires and iron made objects have been also located during the visual inspection of the selected targets. 


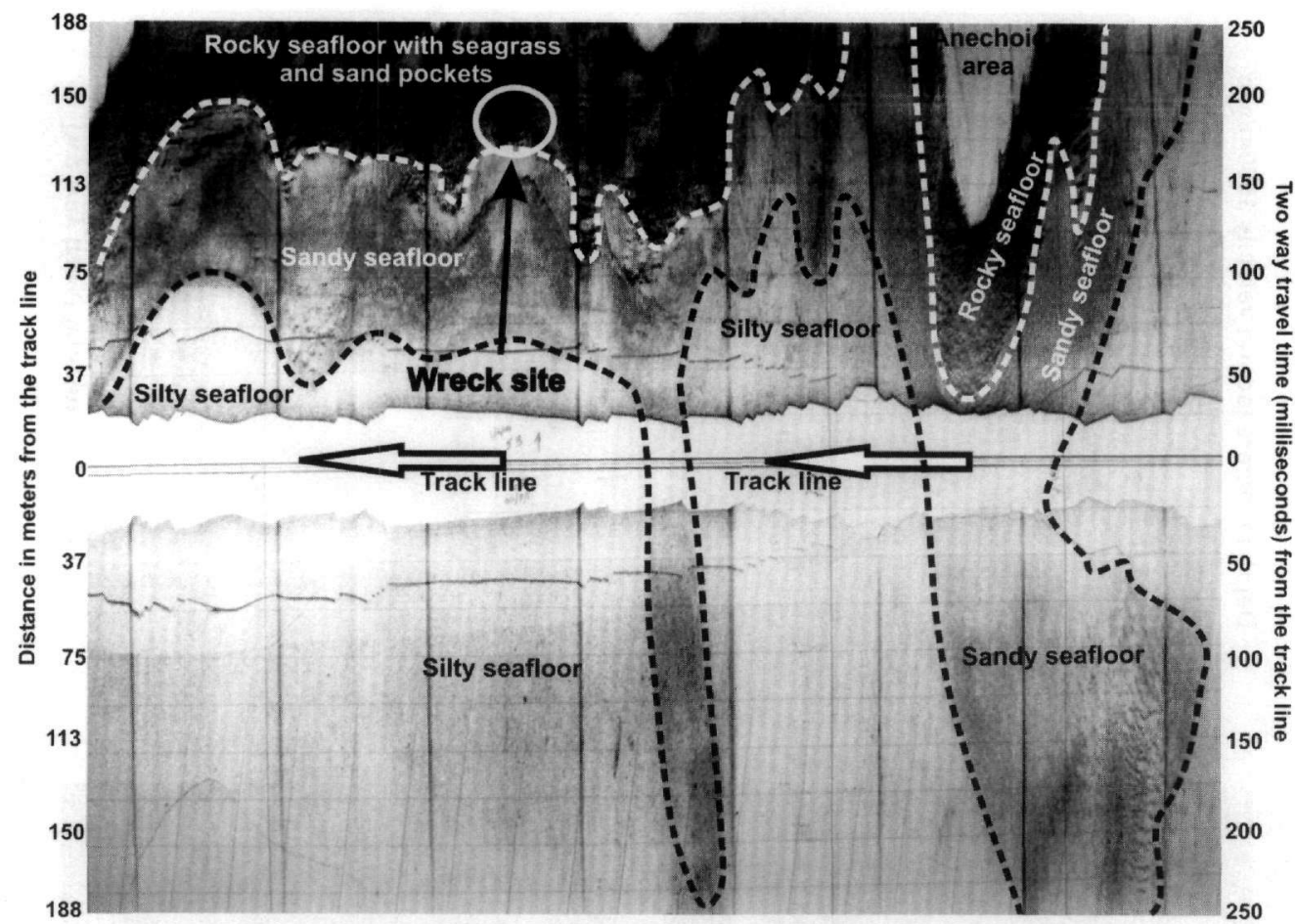

Figure 6 - Interpreted side scan sonar record from the northern coastal slope of Samiopoula islet. See text for explanation. The anechoic areas (reflection-free, white areas at the top of the record) mark the rocky shore of the islet

\subsection{Shallow Water Survey}

If searching for ancient shipwrecks in deep waters is a quite difficult task, the difficulty increases exponentially when the survey area is located in shallow waters, close to the shoreline. The coastal environment is known to be the scene of extensive biogenic, geologic and oceanographic processes, which play a very important role in the development and nature of the seafloor.

The majority of the known ancient shipwrecks has been discovered at shallow depths $(<50 \mathrm{~m})$, in short distances from nearby rocky shorelines. The experience, gained from the repetitive efforts to apply the marine geophysical methodoloGy and instruments in the search for ancient shipwrecks close to steep, rocky shorelines, is not encouraging. In such areas the seafloor displays a very complex character. Extensive or not seagrass meadows, spatial alteration of coarse and fine grain deposits, rocky basement or loose rocks, coastal debris and other natural or anthropogenic objects form a multivariable environment. The interpretation of the side scan sonar recordings from such areas and the recognition of a certain acoustic target / possible wreck within the very complex acoustic record may well be proved to be almost impossible.

Figure 6 shows an interpreted side scan sonar record from the northern slope of Samiopoula islet, south of Samos island. The complexity of the image is obvious. The interpretation is largely based on the information on the seafloor character, which were collected by the ROV dives. The white circle marks the location of an ancient wreck. The wreck was not recognized from the sonar recordings, but was found following the information provided by an old sponge-diver. An impressive concentration of amphorae, reflecting the initial shape of the vessel, was sitting on the seafloor and was hardly recognizable within the seagrass meadows, the rocky outcrops and the sand pockets around it. 


\section{Conclusions}

Remote sensing techniques are a powerful tool for deep-water archaeological research, especially for the detection of archaeological sites, like shipwrecks, beyond diving depths. Conventional marine geophysical methods of seafloor survey provide valuable information on the character of the seafloor and its substrate. Nevertheless their use becomes all the more effective, when the principles of oceanography and marine geology are being followed during the interpretation of the geophysical recordings. Thus, conclusions on the nature of sonar targets, drawn solely from the interpretation of the side scan sonar recordings and the acoustic characteristics of the targets, may be erroneous or may be in direct discrepancy with the shallow sub-seafloor geological structure of the surveyed area. The integration of sub-bottom profiling data provides valuable information on the geological structure of the seafloor's shallow substrate, which are an almost absolute prerequisite for a geologically reasonable interpretation of the side scan sonar images.

Nevertheless, even sonar targets, chosen on the basis of the integration of side scan sonar and subbottom profiling data and the correct geological interpretation of the recordings, may well be of no archaeological significance. Backscatter images derived from features of biogenic origin, like large benthic organisms, bivalves etc. or other objects of anthropogenic origin may be easily misinterpreted as possible wrecks. Finally, a much higher degree of difficulty has to be expected when searching for archaeological remain in shallow water environments due to the complex character of the seafloor.

\section{Acknowledgments}

The author greatly acknowledges the colleagues of the Hellenic Centre for Marine Research and of the Ephorate of Underwater Antiquities, who participated to the various joined EUA-HCMR research cruises and made possible the collection of the data presented here. His thanks go also the officers and the crew of R/V AEGAEO for their valuable support during the cruises.

\section{References}

Ballard, R. D., McCann, A. M., Yoerger, D., Whitcomb, L., Mindell, D., Oleson, J., Singh, H., Foley, B., Adams, J., Piechota, D., and Giagrande, C., 2000. The discovery of ancient history in the deep sea using advanced deep submergence technology, Deep-Sea Research $I, 47,1591-1620$.

Barto Arnold III, J., Oertling, T. J., and Hall A. W., 1999. The Denbigh project: initial observations on a Civil War blockade-runner and its wreck-site, IJNA, 28, 126-144.

Blondel, P., and Pouliquen, E., $\square 004$. Acoustic textures and detection of shipwreck cargo example of a Roman ship near Elba, Italy, In T. Akal, R.D. Ballard and G.F. Bass (eds), Proceedings of the Conference on: The application of recent advances in underwater detection and survey techniques to underwater archaeology, 135-142pp., Bodrum, Turkey.

Chalari, A., Christodoulou, D., Papatheodorou, G., Geraga, M., and Ferentinos, G., 2003. Marine geophysical investigation around the site of the famous Pharos of Alexandria (Egypt) for the detection of ancient shipwrecks, in $2^{\text {nd }}$ World Congress. Ancient Greece "The Modern World”, International Olympic Academy, 62-73pp., Ancient Olympia, Greece.

Hobbs, C. H., Blanton, D. B., Gammisch, R. A., and Broadwater, J., 1994. A marine archaeological reconnaissance survey using side scan sonar, Jamestown, Virginia, USA, Journal of Coastal Research, 10, 351-359.

Kourkoumelis, D., Micha, P., Theodoulou, Th., and Sakellariou D., 2005. Recherches archéologiques sous-marines en Mer Égée, in Procceddings 9th Int. Symp. on "Ship Construction in Antiquity", August 25-30, 2005, Cyprus. 
Quinn, R., Bull, J. M., Dix, J. K., and Adams, J. R., 1997. The Mary Rose site - geophysical evidence for palaeo-scar marks, IJNA, 26, 3-16.

Quinn, R., Adams, J. R., Dix, J. K., and Bull, J. M., 1997. The Invincible (1758) site - an integrated geophysical assessment, IJNA, 27/2, 126-138.

Quinn, R., Cooper, A. J. A. G., and Williams, B., 2000. Marine geophysical investigation of the inshore coastal waters of Northern Ireland, IJNA, 29, 294-298.

Quinn, R., Breen, C., Forsythe, W., Barton, K., Rooney, S., and O'Hara, D., 2002a. Integrated geophysical surveys of the French Frigate La Surveillante (1797), Bantry Bay, Co. Cork, Ireland, Journal of Anthropological Science, 29, 413-422.

Quinn, R., Forsythe, W., Breen, C., Dean, M., Lawrence, M., and Liscoe, S., 2002b. Comparison of the Maritime Sites and Monuments Record with side scan sonar and diver surveys: a case study from Rathlin Island, Ireland, Geoarchaeology, 17, 441-451.

Papatheodorou, G., Stefatos, A., Christodoulou, D., and Ferentinos, G., 2001. Remote sensing in submarine archaeology and marine cultural resources management: an ancient shipwreck outside Zakynthos Port, Greece, In $7^{\text {th }}$ Conference on Environmental Science and Technology, vol. C, 377-385pp.

Papatheodorou, G., Geraga, M., and Ferentinos, G., 2005. The Navarino Naval Battle Site, Greece - an integrated remote-sensing survey and a rational management approach, IJNA, 34, 95109

Sakellariou, D., Kourkoumelis, D., Mallios, A., Micha, P., Georgiou, P., Kapsimalis, V., and Dellaporta, E., 2006. ROV and submersible dives to the deepest known Hellenistic age wreck in the Aegean Sea: KYTHNOS-I, Cyclades Archipelago, Central Aegean Sea, in Proceedings of the International Conference on "Diving for Science and Archaeology", organized by the Society for Underwater Technology, March, 21-22, in conjunction with Oceanology International 2006. London 2006

Sakellariou, D., Kourkoumelis, D., Georgiou, P., Micha, P., Mallios, A., Theodoulou, T., Kapsimalis, V., and Dellaporta, K., 2007. Searching for ancient shipwrecks in the Aegean Sea: The discovery of Chios and Kythnos Hellenistic wrecks with the use of marine geological-geophysical methods, $I J N A$, in press. 